\title{
LAZER, CULTURA E CONSUMO
}

Gisela B. Taschner

Professora Titular do Departamento de Fundamentos

Sociais e Jurídicos da Administração da EAESP/FGV

e Coordenadora do Centro de Estudos de Lazer e

Turismo da EAESP/FGV.

E-mail: gtaschner@fgvsp.br

\section{RESUMO}

Os elos entre lazer e consumo, em sua maioria, são facilmente perceptíveis em nossa sociedade. Nas Ciências Sociais, no entanto, eles nem sempre foram teorizados conjuntamente. O objetivo deste artigo é mostrar como o lazer e o consumo se entrelaçaram na História Ocidental, examinando alguns momentos-chave desse processo, no âmbito da formação de uma cultura do consumo, bem como algumas de suas implicações sobre a sociedade e sobre o comportamento do consumidor. Analisamos também as relações atuais entre lazer e consumo e comentamos algumas tendências para o futuro próximo.

\section{ABSTRACT}

The links between leisure and consumption are very easily perceptible in our society, at least some of them. Nevertheless, they have not always been theorized together in the Social Sciences. The purpose of this article is to examine how leisure and consumption got interwoven in Western History, by focusing some key moments of that process, in the context of formation of a consumer culture, and by taking into consideration some of their impacts on social life and consumer behavior. We also make some comments on the present configuration of the links between leisure and consumption and on some trends they present for the near future.

\section{PALAVRAS-CHAVE}

Lazer, cultura do consumo, comportamento do consumidor, cultura, turismo.

\section{KEY WORDS}

Leisure, consumer culture, consumer behavior, culture, tourism. 
"No society can surely be flourishing and happy, of which the far greater part of the members are poor and miserable."

Adam Smith

Os elos entre lazer, cultura e consumo são facilmente perceptíveis em nossa sociedade, ainda que uns mais do que outros. Há uma dimensão de lazer em algumas formas de consumo, como, por exemplo, ir a um shopping center aos domingos e feriados (para pessoas que gostam de fazer isso, obviamente). Há, também, uma dimensão de consumo no lazer: a maioria das atividades de lazer é, hoje, mediada pelo mercado - ir ao cinema, viajar a turismo, ver TV e conversar pela Internet são alguns exemplos.

O lazer do século XX tem sido estudado tanto em relação ao trabalho (e.g. Friedmann, 1956; Friedmann e Naville, 1961; Dumazedier, 1962) quanto em relação ao processo de mercantilização do tempo livre e da cultura na sociedade capitalista industrial (e.g. Adorno, 1973; Marcuse, 1973 e, em outra linha, Lazarsfeld e Merton, 1971). Ele tem sido analisado principalmente a partir de perspectivas ancoradas na produção.

Assim, nem sempre o lazer e o consumo foram teorizados juntos nas Ciências Sociais, e a dimensão do consumo no lazer tem recebido mais ênfase que a sua recíproca.

Em estudos mais recentes - a maioria dos quais tendo o consumo por foco-, o lazer tem sido abordado primariamente como parte da cultura contemporânea do consumo. É nessa perspectiva que se enquadra o presente artigo. Nossos objetivos são examinar como o lazer e o consumo se entreteceram na História Ocidental no contexto da formação de uma cultura do consumo, dando relevo a momentos-chave desse processo, analisar alguns aspectos da configuração atual de seus laços e comentar algumas tendências para um futuro próximo.

Sem qualquer pretensão de esgotar o tema, será usada aqui uma definição clássica de lazer: "Le loisir est un ensemble d'occupations auxquelles l'individu peut s'adonner de plein gré, soit pour se reposer, soit pour se divertir, soit pour développer son information ou sa formation désinteressé, sa participation social volontaire ou sa libre capacité créatrice après s'être dégagé de ses obligations professionnelles, familiales et sociales" (Dumazedier, 1962, p. 29) ${ }^{1}$.

É importante notar a presença de uma dimensão subjetiva na concepção de lazer de Dumazedier. É o indivíduo que, em última instância, decide o que ele vive e o que ele não vive como lazer.

\section{Se, do ponto de vista de} Veblen, o consumo conspícuo conferia prestígio a uma pessoa, para Elias, o prestígio advinha do fato de ela participar da vida da Corte Real.

A noção de consumo, por sua vez, abarca, neste artigo, a aquisição, a posse e/ou o uso (incluindo a exibição) de bens ou serviços. Ela refere-se sempre ao varejo e ao consumo final. Do mesmo modo, o consumidor será entendido como consumidor final.

Quanto à cultura, estaremos pensando sempre em um tipo específico de cultura: a cultura do consumo.

Quando se pode falar em cultura do consumo? Uma possibilidade é a partir do momento em que "não uma profusão de bens, mas a imagem e a visão de uma profusão de mercadorias aparentemente ilimitada" se generalizam na sociedade (Williams, 1991, p. 3). A cultura do consumo abrange todo um conjunto de imagens, símbolos, valores e atitudes que se desenvolveram com a Modernidade, que se tornaram positivamente associados ao consumo (real ou imaginário) de mercadorias e que passaram a orientar pensamentos, sentimentos e comportamentos de segmentos crescentes da população do chamado Mundo Ocidental.

\section{篎}

O elo teórico entre lazer e consumo começou a ser estabelecido em reflexões pioneiras sobre este último. Foi esse o caso da clássica análise daquela que Veblen chamou de classe 
ociosa (em inglês, leisure class) - basicamente a nobreza e o clero. Como se sabe, a classe ociosa era, de acordo com Veblen, aquela que se dedicava a empregos não rotineiros que envolviam atos de coragem. Tais empregos eram muito prestigiados e incluíam atividades de governo, de guerra, religiosas e esportivas (Veblen, 1934, p. 2).

\section{Como atividade, o consumo dos} membros da classe ociosa não estava necessariamente associado a prazer, diversão ou relaxamento.

Veblen associou o consumo conspícuo ${ }^{2}$ ao advento daquela classe ociosa, que teria atingido seu desenvolvimento máximo no Feudalismo. Assim, o lazer foi associado precisamente àquela classe que não realizava nenhum trabalho produtivo.

De acordo com Veblen, o consumo conspícuo era um meio de aquisição, manutenção e/ou exibição de status social dentro da classe ociosa. Ele diz que "o motivo que está na raiz da propriedade é a emulação [e que] a posse de riqueza confere honra; é uma distinção baseada na inveja" em um contexto de competição social que se desenvolve junto com a propriedade privada. Veblen reconhece a importância de "ganhar a vida" e da busca de maior conforto físico como um motivo para a aquisição - especialmente para a população mais pobre. No entanto, ele diz que, nas comunidades em que a propriedade privada é dominante, "a predominância da vontade não é tão decisiva quanto algumas vezes se assume que seja". Veblen ainda sustenta que, no que se refere às classes que estão visando à acumulação de riqueza, "o incentivo da subsistência ou do conforto físico nunca tem papel preponderante" e é muito enfático quando afirma que "a base sobre a qual a propriedade começou e tornou-se uma instituição humana não tem relação com o mínimo de subsistência. $\mathrm{O}$ incentivo dominante foi, desde o início, a distinção invejosa ligada à riqueza" (Veblen, 1934, p. 25-26).
Em um primeiro momento, a riqueza era uma questão de adquirir, por meio da bravura, troféus de botins. À medida que a atividade industrial cresceu e superou os hábitos predatórios da comunidade, a propriedade acumulada substituiu velhos troféus adquiridos por bravura e ganhou importância como "o expoente convencional de prepotência e sucesso" e como uma "base habitual de reputação e estima”. Em outras palavras, se a reputação de alguém estivera, no passado, atrelada à coragem, da qual os troféus eram mera evidência, ela se vinculou, posteriormente, à posse de bens; a partir de então, tornou-se "necessário atingir um padrão de riqueza um tanto indefinido" (Veblen, 1934, p. 30) para ser bem visto pela comunidade e, em conseqüência, pelos próprios olhos.

De acordo com Veblen, isso deu lugar a uma corrida sem fim das pessoas para atingir um certo padrão que, por sua vez, era apenas o ponto de partida para um outro aumento no nível de riqueza, de modo a se situar mais alto que os competidores na luta pela força pecuniária e reputação. É um processo sem fim, pois sua base é "o desejo de cada um de superar os outros na acumulação de bens". Tal corrida permanece dominante na moderna sociedade industrial (Veblen, 1934, p. 31-32).

Aqui, portanto, podemos ver um primeiro elo entre consumo (consumo conspícuo) e a classe ociosa. Os hábitos de consumo daquela leisure class não estavam, no entanto, associados com o lazer, tal como é entendido no sentido contemporâneo. Eles estavam ligados antes a rituais (de aquisição, de consumo) que atuavam, por sua vez, como sinalizadores sociais e como meios de competição social. Os membros da classe ociosa sentiam que eles "tinham de" acumular riqueza e exibi-la por meio do consumo conspícuo. Como atividade, aquele consumo não ocorria necessariamente no "tempo livre", em oposição a um "tempo de trabalho". Ele não estava necessariamente associado a prazer, diversão ou relaxamento.

$$
\text { m }
$$

A lógica subjacente ao tipo de consumo analisado por Veblen torna-se mais inteligível quando levamos em conta a descrição que Norbert Elias fez da vida da Corte Real na França do Ancién Régime (Elias, 1985). 
De fato, como é amplamente sabido, a nobreza francesa transformou-se entre o fim do Período Medieval e o século XVII, à medida que o rei centralizou o poder, no processo que levou ao Absolutismo e ao Estado Moderno.

Foi naquele contexto que a Corte Real se desenvolveu e se tornou o principal centro de integração da sociedade francesa. Nômade no início, a Corte foi se estabelecendo, primeiro em Paris e depois em Versailles, à medida que aquele processo atingia seu ápice, sob o reinado de Louis XIV.

A análise de Elias deixa claro que todo o luxo do estilo de vida da nobreza na Corte de Louis XIV, assim como o tipo e o volume de consumo que ele implicava, era parte das obrigações da aristocracia (noblesse oblige) para pertencer à Corte Real (ou permanecer nela).

$\mathrm{Na}$ verdade, ocorreu um processo civilizador na vida da Corte: desenvolveu-se, naquela época, um conjunto de regras de etiqueta que faria as pessoas refrear seus impulsos, sua agressividade, suas emoções, assim como ruídos, odores e algumas funções do corpo humano (Elias, 1994).

A nova etiqueta também levou ao desenvolvimento de diversos atos rituais, envolvendo a rotina do rei e dos nobres que participavam ativamente deles; eles expressavam a sujeição dos nobres à realeza, de um lado, e a crescente distância social entre os cortesãos e o resto da população, de outro.

O processo civilizador e o estilo de vida desenvolvido na Corte transformaram profundamente os hábitos de consumo. Passou-se a comer sentado à mesa, usando talheres e pratos individuais: o garfo de servir apareceu no final da Idade Média, o garfo de comer começou a ser usado no século XVI - e ainda era um luxo no século XVII (Elias, 1994, p. 5455). A arquitetura, a decoração de interiores e a mobília das residências mudaram bastante, dando origem a uma série de novos itens de consumo.

Na perspectiva de Elias, portanto, a relação entre consumo conspícuo e prestígio na França do Ancién Régime era um tanto distinta daquela percebida por Veblen. Se, do ponto de vista de Veblen, o consumo conspícuo conferia prestígio a uma pessoa, para Elias, o prestígio advinha do fato de ela participar da vida da Corte Real. Para permanecer na Corte, no entanto, era vital ter um pa- drão muito alto de consumo. Isso requeria riqueza própria ou tornava aquele que efetuava os gastos cada vez mais dependente do rei (Elias, 1985, p. 48-49). ${ }^{3}$

\section{A competição entre a nobreza inglesa levou a uma mudança no padrão de consumo dessa classe: um padrão baseado na pátina deu lugar a um padrão baseado na moda (fashion).}

Em outras palavras, aquele tipo de consumo deve ser olhado dentro de uma lógica política, que estava um tanto distante da lógica burguesa de consumo e de alguns de seus atuais significados e circunstâncias. Se tomamos o caso da França como paradigma, percebemos que é o desenvolvimento do Estado Moderno que subjaz ao novo padrão de consumo da Corte Real e, portanto, à formação da sociedade de consumo contemporânea.

As mudanças nos padrões de consumo das Cortes Reais, tanto quantitativas como qualitativas, tinham a ver com a lógica de sobrevivência da nobreza, que passava pela necessidade de obter e manter o reconhecimento e o favor do rei (ou da rainha). À medida que a realeza passou a usar o luxo e as cerimônias como meio de governar e de exibir poder e à proporção que os nobres se tornavam dependentes do rei, eles tinham de participar das festas, dos bailes, das recepções, etc. para poder permanecer na Corte. Seu consumo conspícuo era um "consumo de prestígio", e não um consumo discricionário, ao contrário do que poderia parecer à primeira vista, e ele não tinha nada a ver com diversão ou prazer.

\section{策}

Ao analisar a centralização do poder real no século XVI na Inglaterra, McCracken (1990) descreve um processo que é bastante similar ao francês. Ele mostra como a nobreza britânica se enfraqueceu economicamente e se tornou dependente da rainha Elizabeth I; 
indica também como esta última começou a usar rituais e o luxo como meio de exercer o poder (ver também Braudel, 1992) - inspirada em alguns príncipes italianos do Renascimento, do mesmo modo que Louis XIV faria mais tarde - e como os nobres foram lançados em uma competição entre si, na

\section{A Corte Real foi o berço de}

um novo padrão de consumo, baseado na renovação constante dos itens de consumo e com espaço para adaptações individuais de tendências dominantes.

Corte, pela atenção real. Ele afirma, ainda, que tal competição levou a uma mudança no padrão de consumo da nobreza inglesa: um padrão baseado na pátina deu lugar a um padrão baseado na moda (fashion).

A pátina é aquele brilho acetinado que aparece em objetos de metal e de madeira após muitos anos de manuseio. O padrão de consumo da nobreza que McCracken chama de pátina (McCracken, 1990, cap. 2) se formara no Período Medieval e tinha a família como unidade de consumo. Cada família devotavase ao "culto do status familiar" e cada geração sentia-se responsável pelos bens que tinha herdado e tentava adicionar algo mais ao patrimônio familiar herdado para legar às gerações seguintes. Naquele contexto, cada geração "buscava bens que manteriam e aumentariam as ambições de status das gerações seguintes". Portanto, "esses bens precisavam ter características especiais. Era necessário que tivessem a habilidade peculiar e misteriosa (de um ponto de vista contemporâneo) de ganhar valor à medida que ficassem mais velhos $\mathrm{e}$ decrépitos. De acordo com a ideologia de status então prevalecente, a novidade era marca de vulgaridade, enquanto a pátina de uso era sinal e garantia de posição" (McCracken, 1990 , p. 13). Os objetos patinados representavam riqueza antiga e ancestrais prestigiosos. Era esse o padrão de consumo baseado na pátina. Segundo McCracken, na dura competição pelo favor real na qual tinham sido jogados na Inglaterra, os nobres mudaram seu padrão de consumo. Começaram a gastar mais com eles próprios, individualmente, do que com suas famílias. Reformaram suas casas de campo, tornando-as muito mais sofisticadas e passaram a ter a despesa adicional de manter uma outra casa em Londres (McCracken, 1990, p. 11). Elevaram seu padrão de hospitalidade, passando a hospedar outros nobres, e tinham de estar prontos para receber, eventualmente, a rainha. Passaram a gastar muito mais com banquetes e vestuário.

Além de outros efeitos, "bens que tinham sido adquiridos para atender a demandas imediatas de uma guerra social assumiam características muito diferentes. Não precisavam mais ser feitos com a preocupação de durar muito nem teriam seu valor crescendo à medida que ficassem velhos. Alguns produtos revelavam-se valiosos não por sua antigüidade, mas sim por serem novidades" (McCracken, 1990, p. 14).

É importante observar que o consumo conspícuo existiu em vários locais e épocas. Dessa vez, entretanto, havia algo diferente acontecendo: era o culto da novidade, do que era diferente - e não apenas do luxo -, que ganhava consistência no consumo da Corte britânica a partir do final do século XVI. Esse é o princípio da moda (fashion) (Lipovetsky, 1989), que encontrou ali um solo fértil para se desenvolver, apesar de manter-se restrito a uma parte pequena da população.

De fato, o desenvolvimento da moda tem sido abordado dentro de um processo no qual a tradição perdeu peso e o presente tornouse a principal referência para as pessoas. Em outras palavras, o desenvolvimento da moda tem sido visto como uma parte da mudança mais ampla que levou à Modernidade. Isso se torna mais claro quando consideramos que o processo no qual a tradição se enfraqueceu está ligado ao desenvolvimento do indivíduo, a partir, grosso modo, do fim da Idade Média. Assim, a moda emergiu como uma das primeiras dimensões na qual o individualismo veio à luz na sociedade ocidental (e.g. Lipovetsky, 1989). ${ }^{4}$

Assim, os casos da França e da Inglaterra sugerem que a Corte Real foi o berço de um novo padrão de consumo, baseado na reno- 
vação constante dos itens de consumo e com espaço para adaptações individuais de tendências dominantes. Tendo atingindo seu ápice na França de Louis XIV, tal padrão difundiu-se para outras classes sociais, como a burguesia da própria França, para outras Cortes na Europa - veja-se, por exemplo, o Palácio de Queluz, construído para a realeza de Portugal para ser uma réplica de Versailles - e para a gentility que cresceu nos EUA (Bushman, 1993; Carson, Hoffman e Albert, 1994).

Após a democratização da sociedade, que ocorreu com as Revoluções Burguesa e Industrial, o estilo de vida prévio da Corte européia - especialmente a francesa - permaneceu como símbolo e referência de finesse, de ser chic, de sofisticação nas sociedades ocidentais. Ainda nos referimos, por exemplo, à mobília "à la Louis XV ou XVI" ou "à la Mme. Pompadour".

A partir do século XIX, o novo padrão difundiu-se para outros segmentos sociais, primeiro, os estratos médios e, depois, as chamadas classes populares. ${ }^{5}$ Entre as possíveis razões para tal difusão - além das econômicas, como acréscimos de renda e queda de preços, em conseqüência da Revolução Industrial -, o desenvolvimento do indivíduo poderia ser mencionado como um estímulo para a ascensão da moda. Em alguns centros, como Paris, por exemplo, a reestruturação urbana facilitou a circulação de pessoas e de mercadorias nas ruas e boulevards, e as Exposições de Paris também tiveram peso ao familiarizar o público com as novidades.

As lojas de departamentos talvez tenham sido as maiores alavancas para tal difusão. Elas promoveram uma revolução na estrutura do comércio varejista e associaram um novo elemento às características do consumo: o prazer que poderia estar presente no processo de compra, real ou imaginário. As lojas de departamentos tornaram mais próxima a relação entre lazer e consumo e, mais do que isso, elas redefiniram essa relação.

$$
m
$$

As lojas de departamentos surgiram em Paris e em Londres na segunda metade do século XIX, após a Revolução Industrial. Logo passaram a ser inauguradas também em grandes cidades dos EUA. No início do século XX, já chegavam a cidades do Terceiro Mundo, como São Paulo e Rio de Janeiro.

Que tipo de inovações elas trouxeram? Leach (1993) mostra algumas delas: para começar, lindas vitrines no exterior e displays dentro da loja. Vidro, cor e luz foram os novos elementos usados com profusão nas fachadas. Todas as possíveis barreiras entre o consumidor e a loja propriamente dita foram removidas; muitas entradas, com portas giratórias, foram colocadas nessas lojas; dentro

\section{A partir do século XIX, o novo padrão difundiu-se para outros segmentos sociais, primeiro, os estratos médios e, depois, as chamadas classes populares.}

delas, corredores amplos e escadas rolantes facilitavam a circulação. Tornou-se possível tocar as mercadorias, diferentemente do que ocorria nas antigas lojas, que, literalmente, escondiam os produtos para evitar que se sujassem; os produtos passaram a ter etiquetas com preços: acabava-se o espaço para a barganha, mas os clientes podiam saber facilmente os preços sem ter que perguntar e sem se sentir forçados a adquirir os produtos que examinavam. Além disso, as lojas eram seguras. Eram novos espaços nos quais se podia andar, tocar nos produtos, experimentá-los e sair dali sem comprar nada.

Por meio dos displays e das vitrines, as lojas de departamentos familiarizavam as pessoas com os produtos disponíveis para venda e, mais do que isso, mostravam o que combinava com o quê.

Em outras palavras, as lojas de departamentos tiveram uma função pedagógica, agindo na socialização dos consumidores. Elas causaram uma impressão tão forte nas pessoas daqueles tempos que houve um aumento no número de furtos, assim como de casos de cleptomania (Leach, 1993, cap. 2-3).

De qualquer modo, o importante a notar é que as lojas de departamentos tornaram muito agradável e divertida a experiência de olhar 
vitrines, zanzar nas lojas e fazer compras, independentemente daquilo que se comprasse ou se deixasse de comprar. Para muitas pessoas, sair para "fazer compras" tornou-se muito prazeroso! Foi assim que o lazer e o consumo se aproximaram na virada do século. ${ }^{6}$

\section{As lojas de departamento}

\section{promoveram uma revolução na}

estrutura do comércio varejista e

associaram um novo elemento às

\section{características do consumo: o prazer.}

Outro fato que merece ser mencionado é o desenvolvimento da publicidade. Ela ganhou um impulso no início deste século, especialmente com a emergência de uma imprensa popular (tanto na Europa como nos EUA) e, mais tarde, de outros meios de comunicação de massa.

Junto com a publicidade, o marketing começou a crescer nos EUA (Belk, 1995). O processo de sedução do consumidor que vimos nas lojas de departamentos fortaleceu-se com a publicidade e, depois, com o marketing. Assim, o desenvolvimento dos mass media foi alimentado também.

Se considerarmos também que a busca constante de oportunidades de negócios no capitalismo industrial levou à expansão da lógica mercantil para novas dimensões da sociedade, vamos desembocar na indústria cultural (ou cultura de massa, como ela é também conhecida) e no processo de mercantilização do lazer após a Segunda Guerra Mundial. Na verdade, o lazer tornou-se, ele próprio, objeto de uma indústria ou de um complexo de serviços, para sermos mais precisos. De automóveis e cinemas ao turismo, a parques temáticos e a equipamentos de lazer domésticos, ${ }^{7}$ a maior parte do lazer contemporâneo está mediada por produtos ou serviços vendidos em um mercado de massas.

Assim, todos esses processos levaram ao desenvolvimento de uma cultura do consumo, a qual se difundiu por quase todas as sociedades ocidentais, primeiramente, no cha- mado Primeiro Mundo e, depois, em muitos outros países.

A formação e a configuração de sociedades de produção e consumo de massa já foram estudadas por abordagens tradicionais, do Funcionalismo ao Marxismo e à Escola de Frankfurt. Aqui, os resultados de análises mais tradicionais (funcionalistas, estruturais ou historicistas) convergem para aqueles obtidos a partir de estudos sociológicos e culturais mais recentes: vemos claramente a dimensão do consumo crescendo dentro do tempo de lazer - o qual é visto, atualmente, como o tempo livre daqueles que têm trabalho ou emprego (Friedmann, 1956; Friedmann e Naville, 1973) - e podemos ver também a dimensão do lazer crescendo dentro da cultura do consumo e dentro dos processos e hábitos de consumo (e.g. Lazarsfeld e Merton, 1971; Marcuse, 1973; Wright Mills, 1956; Featherstone, 1991).

$$
\text { m }
$$

Como sabemos, desde os anos 70 e 80, vêm ocorrendo algumas mudanças profundas em nossa sociedade (e.g. Naisbitt, 1984; Naisbitt e Aburdene, 1990; Popcorn, 1994).

Estamos atravessando um processo de "despadronização" da produção e do consumo. Nossa base produtiva industrial vem se transformando em uma estrutura informatizada, que acelera a velocidade dos fluxos de informação e torna flexível a produção antes rígida.

Nas organizações (não somente nas empresas), as hierarquias típicas da pirâmide burocrática de Weber vêm-se achatando e passaram a coexistir com estruturas de redes.

O processo de globalização tem caminhado também com a sua contrapartida de reafirmação de identidades locais e regionais.

Como essas transformações afetam o lazer e o consumo na cultura ocidental contemporânea e, mais particularmente, a relação entre ambos? Abre-se, aqui, muito espaço para se "pensar em voz alta", mas muito pouco ou mesmo nenhum para afirmações fechadas. Tendo-se isso em mente, podemos apenas sugerir que alguns pontos sejam objeto de consideração no esboço de alguma resposta.

\section{Os laços entre lazer e consumo tendem a manter-se e a estreitar-se em algumas}


áreas e para algumas pessoas. Seu casamento tende a ser duradouro desde que se ajuste a algumas tendências da sociedade e do mercado.

- Customização de massa: ela vem substituindo o marketing de massas e a busca do "homem médio" por estratégias de segmentação focadas nos consumidores reais e desejados. No caso-limite, a segmentação tende à personalização dos produtos/serviços, tirando partido das possibilidades abertas pela produção flexível e apontando para uma real despadronização da produção e do consumo (Feather, 1994). Quando referidas à globalização, no entanto, essas estratégias apontam para uma customização de massa (Levitt, 1990), ${ }^{8}$ assumindo-se que a maioria dos segmentos locais tem seus homólogos em outros países e tentando-se recompor, em um nível internacional, as economias de escala que foram tão importantes para os lucros na época da produção rígida. Assim, o lazer mercantilizado tende a ser customizado em massa, do mesmo modo que outros produtos e serviços.

- Sensibilidade a diferenças culturais: no início dos anos 80, Theodore Levitt afirmava - em seu artigo pioneiro sobre a globalização - que "as necessidades e os desejos" tinham se "homogeneizado no mundo de modo irreversível". Isso tornaria "obsoleta a empresa multinacional e absoluta a empresa global" (Levitt, 1990, p. 54). ${ }^{9}$ A pesquisa mais recente, entretanto, aponta para uma direção oposta: as diferenças culturais vêm ganhando importância (foram elas que aumentaram ou aumentou nossa sensibilidade em relação a elas?) tanto de um ponto de vista econômico (Hofstede, 1991; Howes, 1996; Usunier, 1996) como político; tais diferenças têm impacto tanto sobre as preferências dos consumidores como sobre o papel do lazer e do consumo nas suas vidas.

- Ajustes ao espaço virtual e a novas estruturas de trabalho e emprego: disponibilidade de lazer e de consumo tanto dentro como fora de casa. As previsões de Feather (1994) para o processo de fazer compras nos EUA no futuro próximo falam de compras virtuais - ou seja, feitas no espaço cibernético - para um nú- mero muito grande de itens. Em tal cenário, os shopping centers "de verdade" ícones contemporâneos do consumo - tenderão a ser usados principalmente para atividades de lazer e correlatas. Por outro

\section{Os resultados de análises mais} tradicionais mostram, entre outros fatores, a dimensão do lazer crescendo dentro da cultura do consumo e dentro dos processos e hábitos de consumo.

lado, os equipamentos domésticos de entretenimento vêm ganhando importância, como já mencionamos antes, e tendem a ganhar mais importância ainda se continuar a aumentar o número de pessoas que trabalham em casa. Nesse caso, as fronteiras entre trabalho, lazer e consumo podem se tornar mais indefinidas do que em qualquer época anterior do capitalismo, por causa da natureza do trabalho (mental), em virtude do local em que o trabalho passa a ser feito (em casa), em função dos meios de trabalho (computadores) ou da flexibilidade dos horários de trabalho desse tipo de trabalhador.

2. O advento da Internet muda a estrutura do lazer na área relacionada ao consumo de produtos culturais.

Não há sinais de mudanças profundas na estrutura do lazer relacionado à indústria cultural em virtude de a TV a cabo, apesar de trazer um número maior de canais, não ser estruturalmente distinta da TV aberta. Os canais particulares de ambas trabalham de acordo com a mesma lógica. Sob uma perspectiva frankfurteana, isso significa que a alienação inerente ao trabalho dividido da sociedade industrial tende a continuar a se estender ao lazer.

A Internet, no entanto, é uma inovação que traz rupturas nesse esquema, as quais podem ser o início de uma grande mudança so- 
cial: sendo interativa, sua estrutura é muito mais democrática que as TVs abertas comerciais, pelo fato de haver uma relação muito mais equilibrada entre o número de pessoas que se manifesta e o número de pessoas que "vê/lê/ouve" e que pode inverter os papéis a qualquer momento sem problemas. Isso

\section{O consumo durante o tempo de lazer pode vir a estar direcionado menos a produtos} tangíveis e, mais e mais,
ao consumo de sensações.

equivale a virar de cabeça para baixo a estrutura de comunicação típica da indústria cultural e abre possibilidades para eventuais formas "não alienadas" de lazer, comunicação e consumo.

Em vez de ter que escolher entre as alternativas que os produtores resolveram oferecer, os consumidores podem vir a ter a chance de ser mais ativos na determinação daquilo que deve ser oferecido. O número de horas que as pessoas passam na frente da TV está se reduzindo em benefício da tela do computador e podemos supor facilmente que essa tendência tende a ganhar peso num futuro próximo.

\section{A cultura do consumo tem um espec- tro mais amplo que o acesso efetivo a itens de consumo ou de lazer pela po- pulação.}

Há muita gente excluída do lazer e de muitas formas de consumo, apesar de participar da cultura do consumo. A tendência ao desemprego (Kurz, 1992, entre outros), resultante do uso das novas tecnologias em um contexto de enfraquecimento dos estadosnações, pode tornar esse gap intransponível. Tal exclusão é muito mais profunda no Terceiro Mundo do que no Primeiro e muito mais visível também. A recessão na qual os países de industrialização mais recente (NICs) foram atirados ultimamente vai, provavelmente, aprofundar ainda mais a exclusão. Nesse sentido, o gap entre o Primeiro e o Terceiro Mundo poderá aumentar também.

Num quadro de desemprego crescente, o próprio conceito de lazer pode vir a mudar. A cultura do consumo também estaria ameaçada nesse contexto. Nesse meio-tempo, é possível que continuemos a viver uma situação paradoxal no futuro próximo. Em países mais ricos (do G7, por exemplo), o casamento entre lazer e consumo tende a durar - customizado em massa, algumas vezes virtual, culturalmente orientado - nas camadas ricas e entre aqueles que têm um emprego ou seu próprio negócio ou que são trabalhadores autônomos. Nesses casos, podemos vir a encontrar nichos nos quais o consumo durante o tempo de lazer pode vir a estar direcionado menos a produtos tangíveis e, mais e mais, ao consumo de sensações; para esse segmento, uma "aventura" no Pantanal ou na Amazônia pode se tornar mais atraente que a compra da $300^{\mathrm{a}}$ gravata ou da $100^{\mathrm{a}}$ camisa nas lojas do Primeiro Mundo, desde que se seja trazido de volta para casa em segurança "para o jantar" (veja Popcorn, 1994, p. 31-34).

Em outros segmentos, que são e - ao que tudo indica - tendem a permanecer particularmente abundantes em países do Terceiro Mundo, estaremos propensos a encontrar camadas de baixa renda ou sem emprego que não têm acesso significativo ao mercado real de consumo - especialmente ao consumo de lazer - apesar de participarem da cultura do consumo (por exemplo, o office-boy que usa um tênis Nike comprado a prestação e o pivete que o obtém por meio do roubo).

Não há indícios de mudanças para melhor em um futuro próximo. Ao contrário.

Portanto, é mais ou menos fácil afirmar que o casamento entre lazer e consumo pode ser feliz para alguns daqueles nele envolvidos. Seria muito mais difícil afirmar que ele trouxe mais felicidade a outras pessoas do que quando o consumo e o lazer estavam ainda separados ou que ele trará mais felicidade do que durante a época da sociedade de massas. Afinal, ele pode estar apenas dando alívio momentâneo a alguns de nós, em uma vida vivida em um mundo violento e cheio de riscos.

Para essas questões, ainda não há respostas prontas; há, no máximo, esperança. $\bigcirc$ 


\section{REFERÊNCIAS BIBLIOGRÁFICAS}

ADORNO, Theodor W. Consignas. Buenos Aires : Amorrortu, 1973. Tradução de: Stichworte. Kritische Modelle 2.

BELK, Russell W. Studies in the new consumer behaviour. In: MILLER, Daniel (Ed.). Acknowledging consumpto. London : Routledge, 1995.

BOURDIEU, P. La distincção: critique sociale du jugement. Paris : Les Editions de Minuit, 1979.

BOWDEN, Sue, OFFER, Avner. Household appliances and the use of time: the United States and Britain since the 1920s. The Economic History Review, v. 47, n. 4, p. 725748, Nov. 1994

BRAUDEL, Fernand. Civilization and capitalism 15th 18 th century: the structures of everyday life. Berkeley, LA : University of California Press, 1992. V. 1, cap. 3 e 4 .

BUSHMAN, Richard L. The refinement of America: person houses, cities. New York: Vintage Books, 1993.

CARSON, Cary, HOFFMAN, Ronald, ALBERT, Peter J. (Eds.) Of consuming interests: the style of life in the eighteenth century. Charlottesville/London : University Press of Virginia, 1994.

DUMAZEDIER, Joffre. Vers une civilization du loisir? Paris : Ed. du Seuil, 1962.

ELIAS, Norbert. La societé de Cour. Paris : Flammarion, 1985. Original em alemão. 1a edição alemã de 1969.
ELIAS, Norbert. The civilizing process, 0xford, UK Cambridge, USA : Blackwell, 1994. Original em alemão. 1 edição alemã de 1939, em 2 v

FEATHER, Frank. The future consumer. Toronto : Warwick Publishing Inc., 1994.

FEATHERSTONE, Mike. Consumer culture and postmodernism. London : Sage, 1991.

LAZARSFELD, P., MERTON, Robert. Mass communication, popular taste and organized social action. In: COHN, Gabrie (Ed.). Comunicação e indústria cultural. São Paulo Nacional, 1971. Original em inglês.

LEACH, William. Land of desire: merchants, power and the rise of a new American culture. New York : Vintage, 1993.

LEVITT, Theodore. The globalization of markets. In: ENIS Ben M., COX, Keith K., MOKWA, Michael P. (Eds.) Marketing classics. New Jersey: Prentice-Hall, 1990. p. $53-65$

LIPOVETSKY, Gilles. O império do efêmero: a moda e se destino nas sociedades modernas. São Paulo : Companhia das Letras, 1989. 294 p. Tradução de: L'Empire de l'éphémère: la mode et son destin dans les societés modernes. 1ạ edição francesa, 1987, Gallimard.

MARCUSE, Herbert. Ideologia da sociedade industrial. Rio de Janeiro : Zahar, 1973. Tradução de: One dimensional man.

McCRACKEN, G. Culture and consumption. Bloomington/ Indianapolis : Indiana University Press, 1990.
NAISBITT, John. Megatrends. New York: Warner Books, 1984

NAISBITT, John, ABURDENE, Patricia. Megatrends 2000. New York: William Morrow and Co., 1990.

POPCORN, Faith. The Popcorn report. New York: Doubleday, 1994.

SIMMEL, G. Fashion. International Quarterly, v. 10, p. 130 $155,1904$.

SPENCER, Herbert. Principles of Sociology. New York : D. Appleton, 1897. V. 2, Parte I.

TARDE, Gabriel de. The laws of imitation. Gloucester, MA : P. Smith, 1962

USUNIER, Jean Claude. Marketing across cultures. London : Prentice-Hall, 1996

VEBLEN, Thornstein. The theory of the leisure class. New York: The Modern Library, 1934. 1ª edição de 1899.

WILLIAMS, Rosalind H. Dreamworlds, mass consumption in late nineteenth century France. Berkeley, Los Angeles, Oxford : University of California Press, 1991. 1a edição de 1982.

WRIGHT, Mills. The power elite. New York : Oxford University Press, 1956
NOTAS

0 original deste trabalho, em inglês, foi apresentado no XIV Congresso da International Sociological Association em Montreal, de 26 de julho a 10 de agosto de 1998. Uma segunda versão, em inglês também, foi apresentada no BALAS Meeting, de 4 a 8 de abril de 2000, em Caracas. A versão em português aqui publicada foi apresentada no IX Congresso da Sociedad Brasileira de Sociologia, em Porto Alegre, de 30 de agosto a 3 de setembro de 1999. Agradeço ao CNPq e ao NPP da EAESP/ FGV, que, em distintos momentos, deram apoio à pesquisa que deu base a este artigo.

Este artigo baseia-se em pesquisa financiada pelo NPP Núcleo de Pesquisas e Publicações da EAESP/FGV intitulada "Revolução do consumidor l".

1. Tradução livre: "O lazer é um conjunto de ocupações às quais 0 indivíduo pode se dedicar prazerosamente, seja para relaxar, divertir-se ou para alargar seu conhecimento e sua participacão social espontânea, o livre exercício de sua capacidade criativa, após ter-se desembaraçado de suas obrigações de trabalho, familiares e sociais."

2. Não queremos entrar na discussão sobre a possibilidad ou a impossibilidade de se estabelecerem critérios "objetivos" para diferenciar consumo necessário de consumo conspícuo.
Marx já afirmava que havia um elemento moral e histórico neles, ao estudar 0 valor da força de trabalho. Estamos apenas pressupondo que, em cada sociedade e época, há alguma possibilidade de se estabelecer uma diferença, ao menos nos extremos.

3. Elias afirmou que Veblen jamais entendeu a lógica do consumo conspícuo da nobreza porque ele o pensava em termos de uma lógica burguesa (Elias, 1985, p. 48-49).

4. Isso não significa que a moda não tenha outros determinantes. Sua análise, no entanto, está fora do escopo deste artigo.

5. 0 modelo geralmente empregado para descrever a difusão da moda baseia-se no chamado "trickle down effect", cuja teorização tem raízes atribuídas a Spencer (1897), Veblen (1934), Simmel (1904) e Tarde (1962). Entre os autores contemporâneos, Bourdieu (1979) McCracken (1990) o usam, em versões diferentemente redefinidas.
6. Os shopping centers atuais tornam esse processo mais visível.

7. Nos EUA, o tempo de difusão de inovações em equipamentos domésticos de lazer, como TVs e videocassetes, tem sido muito menor que 0 de difusão de equipamentos "de trabalho", como aspiradores ou máquinas de lavar (Bowden e Offer, 1994).

8. Na verdade, o "foco no cliente" e a customização de massa são conceitos contraditórios. A expressão customização de massa é paradoxal. No entanto, a discussão de tal paradoxo está fora do escopo deste artigo.

9. Levitt estabelece uma diferença entre empresa multinacional e empresa global. A primeira ajusta seu produto a cada mercado a custos relativos mais altos. $A$ segunda tem o mesmo produto para todos e, portanto, faz economia de escala e tem custos relativos menores (Levitt 1990, p. 53). 